\title{
MGMT expression in pituitary corticotroph adenomas and its relationship to clinical, pathological, and ultrastructural parameters in patients with Cushing's disease
}

\begin{abstract}
Przemysław Witek ${ }^{1}$, Maria Maksymowicz ${ }^{2}$, Katarzyna Szamotulska ${ }^{3}$, Agata Piaścik ${ }^{2}$, Agnieszka Wojciechowska-Luźniak ${ }^{1}$, Aleksandra Stasiewicz ${ }^{1}$, Joanna Witek ${ }^{4}$, Grzegorz Zieliński ${ }^{5}$

${ }^{1}$ Department of Internal Medicine, Endocrinology, and Diabetes, Mazovian Bródno Hospital, Medical University of Warsaw, Warsaw, Poland, ${ }^{2}$ Department of Pathology and Laboratory Diagnostics, Maria Curie-Skłodowska National Institute of Oncology, Warsaw, Poland, ${ }^{3}$ Department of Epidemiology and Biostatistics, Institute of Mother and Child, Warsaw, Poland, ${ }^{4}$ Outpatient Clinic, Institute of Mother and Child, Warsaw, Poland, ${ }^{5}$ Department of Neurosurgery, Military Institute of Medicine, Warsaw, Poland
\end{abstract}

\begin{abstract}
Introduction: Transsphenoidal surgery is the treatment of choice in Cushing's disease (CD), although even late recurrences occur in some patients. Low expression of 0-6-methylguanine-DNA methyltransferase (MGMT) has been linked to a high risk of relapse in pituitary tumours, but the evidence for corticotroph adenomas is limited. Therefore, we investigated whether MGMT expression was associated with CD remission or clinicopathological markers of tumour aggressiveness among patients with corticotroph adenomas.

Material and methods: We included 72 consecutive patients ( $83 \%$ female, mean age $\pm S D: 44.15 \pm 15.15$ years) with $C D$, who underwent transsphenoidal adenomectomy between 2012 and 2018. The invasiveness of corticotroph tumours was assessed based on the Knosp scale. Immunohistochemistry was used to analyse MGMT expression as well as the proliferation markers (Ki-67, p53, mitotic index). Electron microscopy was used to categorise tumours into densely or sparsely granulated. Early biochemical remission was evaluated in all patients 6 months after pituitary surgery.

Results: Early remission was observed in 47 (65\%) patients 6 months after surgery. MGMT expression was > 75\% in half of all tumours, $<25 \%$ in 14 tumours, and $25-50 \%$ or $50-75 \%$ in 11 tumours. Lower MGMT expression was associated with a larger tumour diameter $(p=0.001)$, higher adrenocorticotropic hormone (ACTH) concentration $(p=0.002)$, higher $p 53$ expression $(p=0.026)$, and higher frequency of sparsely granulated corticotroph adenomas $(p=0.009)$. Low MGMT expression was significantly related to lower frequency of early clinical remission $(p=0.005)$. Conclusions: MGMT predicted the outcomes of transsphenoidal surgery for CD. Pituitary corticotroph adenomas with low MGMT expression may be associated with increased invasiveness and poorer prognosis.
\end{abstract}

Key words: Cushing's disease, cortisol, MGMT, transsphenoidal surgery, temozolomide.

\section{Communicating author}

Przemysław Witek, MD, PhD, Department of Internal Diseases, Endocrinology, and Diabetes, Mazovian Bródno Hospital, Medical University of Warsaw, Warsaw, Poland, e-mail: pwitek@wum.edu.pl, drpwitek@gmail.com 


\section{Introduction}

Cushing's disease, caused primarily by pituitary corticotroph adenomas, is associated with substantial morbidity and mortality, mainly due to cardiovascular and infectious complications [30]. In most patients with Cushing's disease, transsphenoidal tumour removal can induce remission ( $80 \%$ for microadenomas, $60 \%$ for macroadenomas) [31], but about $20 \%$ of patients have tumour recurrence in the long term $[3,5,13,16,43,45]$. These patients require second-line treatment, such as neurosurgical procedures, radiation therapy, or chemotherapy with temozolomide or other agents [32,35]. However, choosing a particular second-line treatment remains difficult due to a lack of reliable clinical or ancillary criteria.

In patients with pituitary tumours, the expression of 0-6-methylguanine-DNA methyltransferase (MGMT) is a prognostic factor of treatment outcomes: low MGMT tumour expression has been linked to a high recurrence risk of these tumours $[9,11,22]$. MGMT is a DNA repair enzyme that restores mutagenic changes at position 0-6 of methylguanine [18]. Loss of MGMT expression increases carcinogenic risk with many tumour types such as gliomas, lymphomas, or breast cancers [14]. In the central nervous system, MGMT is typically expressed by normal tissue, but primary brain tumours often lack MGMT expression [39].

MGMT expression is also important from a therapeutic standpoint because this enzyme reduces the effectiveness of alkylating chemotherapeutics, including temozolomide $[38,40]$. This type of treatment acts via induction of mutations at position $\mathrm{O} 6$ of guanine [17]. Consequently, low MGMT expression has been also associated with a good response to temozolomide treatment $[1,4,21,24,41]$.

Assessment of MGMT expression in corticotroph pituitary adenomas can help identify patients who are most likely to benefit from temozolomide treatment. However, current evidence on the role of MGMT expression in corticotroph adenomas is scarce. Therefore, we analysed the relationship of MGMT expression in corticotroph tumours with clinical and pathological variables among patients who underwent transsphenoidal pituitary surgery.

\section{Material and methods \\ Study design and cohort}

We included all consecutive patients with Cushing's disease, who underwent transsphenoidal sur- gery between 2012 and 2018 due to corticotroph pituitary adenomas. There were 72 patients who fulfilled the inclusion criteria ( $83 \%$ female; mean age $\pm S D$ : $44.15 \pm 15.15$ years). All operations were done by the same neurosurgeon according to the same protocol. Details of all operative procedures were taken from operative records. A direct transnasal transsphenoidal microscopic approach was performed for selective resection of pituitary adenoma. The study was retrospective, but all data were acquired prospectively during the study period. The study was approved by the local Bioethics Committee.

\section{Clinical and ancillary assessments}

The diagnosis of Cushing's disease was made according to standard criteria [29]. Tumour size was measured on magnetic resonance images (GE Signa, 1.5 Tesla) in the coronal, sagittal, and axial dimensions. The greatest of the three was taken as the maximum tumour diameter, in line with the RECIST criteria. A macroadenoma was defined as a tumour with a maximum dimension $\geq 10 \mathrm{~mm}$. Tumour invasiveness of macroadenomas was assessed according to the Knosp scale [19].

\section{Histopathological assessments}

Histopathological examinations of specimens obtained during surgery were performed in accordance with the 2017 WHO classification [23]. Tissue samples, fixed in $10 \%$ buffered formalin and embedded in paraffin, were routinely stained with haematoxylin and eosin. Immunohistochemical staining was performed according to the labelled EnVision Flex Visualization System (K8000, Dako/Agilent) with 3,3'-diaminobenzidine as the chromogen. Slides with paraffin-embedded tumour samples were immunolabeled with antibodies against the following antigens: growth hormone (cat. no. M5-1328-P1), prolactin (cat. no. M5-1362-P1), ACTH (cat. no. M5-1452-P1), $\beta$-TSH (cat. no. M5-1453-P1), $\beta$-FSH (cat. no. M5-1449-P1), $\beta$-LH (cat. no. MS-1448-P1), and MGMT (clone MT 23.2, cat. no. MA3-16537); all antibodies from Thermo Fisher Scientific. Moreover, the antibodies against the glycoprotein $\alpha$-subunit (cat. no. MCA 1026, Bio-Rad, UK), p53 protein (cat. no. IR 616, DO-7), and Ki-67 (MIB-1 clone, cat. no. IR626), purchased from DAKO/Agilent, were used. MGMT expression was graded in four categories: $<25 \%, 25-50 \%, 50-75 \%$, and $>75 \%$ of cells; the 
Ki-67 labelling index was graded in three categories: $<3 \%, 3-10 \%$, and $>10 \%$ positive nuclei; p53 expression was graded in three categories: < 5\%, 5-50\%, and > 50\% positive nuclei; and mitotic index was graded in two categories: $\leq 2$ and $>2$ mitoses per 10 high-power fields.

Ultrastructural examination was performed with a Philips CM120 BioTWIN transmission electron microscope. Corticotroph adenomas were classified on the basis of commonly accepted ultrastructural features as densely granulated or sparsely granulated.

\section{Hormonal assessments and remission criteria}

Immediate postoperative remission was ascertained when the nadir serum cortisol concentration at 06:00 $\mathrm{h}$ was $\leq 2.5 \mu \mathrm{g} / \mathrm{dl}$ on the first or second postoperative day, as described previously [47]. We used the following criteria for remission at six months after surgery: clinical and biochemical evidence of adrenal insufficiency or, when adrenal function was preserved, biochemical evidence of cortisolaemia: urinary free cortisol, morning serum cortisol, and plasma ACTH levels within their respective reference ranges; preservation of the circadian rhythm of serum cortisol; and serum cortisol after overnight dexamethasone suppression test $\leq 1.8 \mu \mathrm{g} / \mathrm{dl}$.

$\mathrm{ACTH}$ concentrations were measured with an immunoradiometric assay (ELSA-ACTH, CIS Bio International, Gif-sur-Yvette Cedex, France; analytical sensitivity, 2 pg/ml; reference range, 10-60 pg/ml). Serum cortisol concentrations were measured with an electrochemiluminescence immunoassay (Elecsys 2010, Roche Diagnostics; analytical sensitivity, $0.02 \mu \mathrm{g} / \mathrm{dl}$; reference range, 6.2-19.4 $\mu \mathrm{g} / \mathrm{dl}$ ).

\section{Statistical analysis}

Descriptive statistics were used in accordance with data distribution. The Mann-Whitney test was used for comparisons between two groups. The Jonckheere-Terpstra trend test or analysis of variance (ANOVA) were used to study the relationship between the expression of MGMT (categories) and continuous variables. Relationships between categorical variables were tested with the $\chi^{2}$ test or the Fisher exact test. Univariate and multivariate logistic regressions were used to find significant predictors of remission. Dependent variables were treated as ordered in the models. A value of $p<0.05$ was con- sidered statistically significant. All calculations were completed in IBM SPSS software (version 25).

\section{Results}

\section{Patients}

Among 72 patients included in the study remission was ascertained in 44 (61\%) patients immediately after surgery, and in 47 (65\%) patients at 6 months. The remaining cohort characteristics are shown in Table I.

\section{MGMT expression and its relationship with clinicopathological variables}

MGMT expression was > $75 \%$ in half of all tumours, < $25 \%$ in 14 tumours, and $25-50 \%$ or $50-75 \%$ in 11 tumours, respectively. Table II shows the expression of the remaining histopathological markers.

Tumours in men had a lower MGMT expression that those in women $(p=0.004)$. There was no significant relationship between MGMT expression and age $(p=0.217)$.

Higher MGMT expression was associated with a lower tumour diameter ( $p=0.001$; Fig. 1 ) and lower ACTH concentrations at 8:00 ( $p=0.002$; Fig. 2). There was no significant relationship between MGMT expression and morning serum cortisol concentrations ( $p=0.177$ ) or Knosp grade in corticotroph macroadenomas $(p=0.466)$. Higher MGMT expres-

Table I. Baseline characteristics of the study cohort

\begin{tabular}{|c|c|}
\hline Variable & Value \\
\hline Age (years), mean \pm SD & $44.15 \pm 15.15$ \\
\hline Female, $n(\%)$ & $60(83)$ \\
\hline $\begin{array}{l}\text { Maximum tumour diameter (mm), } \\
\text { median (range) }\end{array}$ & $7.5(2-62)$ \\
\hline \multicolumn{2}{|l|}{ Tumour size, $n(\%)$} \\
\hline Microadenoma & $47(65)$ \\
\hline Macroadenoma & $25(35)$ \\
\hline \multicolumn{2}{|l|}{ Knosp grade, $n(\%)$} \\
\hline $0-2$ & $14(56)$ \\
\hline $3-4$ & $11(44)$ \\
\hline ACTH 8:00 (pg/ml), median (range) & $68.65(23-563)$ \\
\hline Cortisol 8:00 ( $\mu \mathrm{g} / \mathrm{ml})$, median (range) & $23.70(10.9-73.4)$ \\
\hline ACTH : cortisol ratio, median (range) & $3.15(1.06-16.73)$ \\
\hline $\begin{array}{l}\text { Cortisol following ODST }(\mu \mathrm{g} / \mathrm{ml}) \text {, } \\
\text { mean } \pm \text { SD }\end{array}$ & $14.46 \pm 8.65$ \\
\hline
\end{tabular}

ACTH - adrenocorticotropin, ODST - overnight dexamethasone suppression test, SD - standard deviation 
Table II. Expression of histopathological markers in corticotroph tumours

\begin{tabular}{|c|c|}
\hline Variable & Value \\
\hline \multicolumn{2}{|l|}{ MGMT, $n(\%)$} \\
\hline$<25 \%$ & $14(19)$ \\
\hline $25-50 \%$ & $11(15)$ \\
\hline $50-75 \%$ & $11(15)$ \\
\hline$>75 \%$ & $36(50)$ \\
\hline \multicolumn{2}{|l|}{ p53, n (\%) } \\
\hline$<5 \%$ & $56(78)$ \\
\hline $5-50 \%$ & $12(17)$ \\
\hline$>50 \%$ & $4(6)$ \\
\hline \multicolumn{2}{|l|}{ Ki-67, n (\%) } \\
\hline$<3 \%$ & $52(72)$ \\
\hline $3-10 \%$ & $17(24)$ \\
\hline$>10 \%$ & $3(4)$ \\
\hline \multicolumn{2}{|c|}{ Mitotic index, $n(\%)$} \\
\hline$\leq 2$ & $67(93)$ \\
\hline$>2$ & $5(7)$ \\
\hline \multicolumn{2}{|c|}{ Electron microscopy ${ }^{*}, n(\%)$} \\
\hline DG-ACTH & $49(79)$ \\
\hline SG-ACTH & $13(21)$ \\
\hline
\end{tabular}

ACTH - adrenocorticotropin, DG - densely granulated, SD - standard deviation, $S G$ - sparsely granulated.

${ }^{*}$ Data available for 62 tumours (too little material for both immunohistochemistry and ultrastructure or normal pituitary tissue in specimen for EM).

sion was related to lower $p 53$ expression $(p=0.026)$ and higher frequency of DG-ACTH tumours on electron microscopy $(p=0.009)$. There was a tendency toward a negative relationship of MGMT expression with the expressions of $\mathrm{Ki}-67(p=0.099)$ and the number of mitotic figures $(p=0.096)$.

Among all the histopathological markers analysed, only MGMT expression was significantly related to early clinical remission ( $p=0.005$; Table III), which was also confirmed after an adjustment for the ultrastructure category in stepwise logistic regression ( $p=0.043)$. This relationship remained a statistical trend after adjustment for tumour size $(p=0.074$, Table IV).

\section{Discussion}

This study confirmed that MGMT is a promising prognostic marker for patients undergoing surgical removal of corticotroph pituitary adenomas. We observed that immediate remission was more likely in patients with corticotroph tumours with high MGMT expression. Moreover, higher MGMT expres-

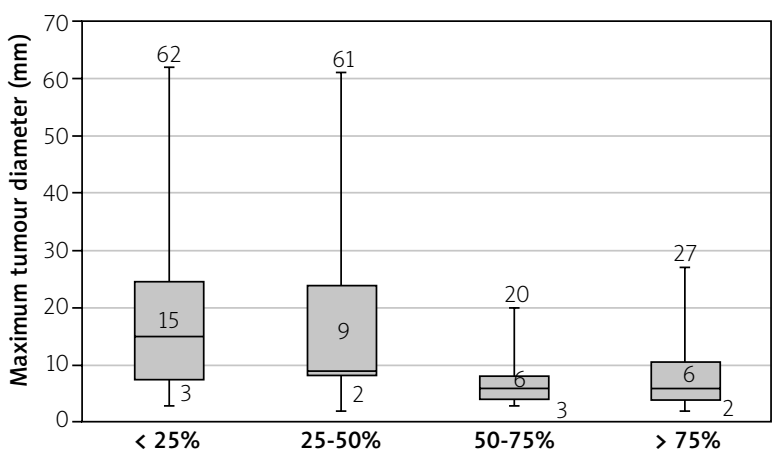

Fig. 1. Maximum tumour diameter (median, interquartile range, and range) by MGMT expression category.

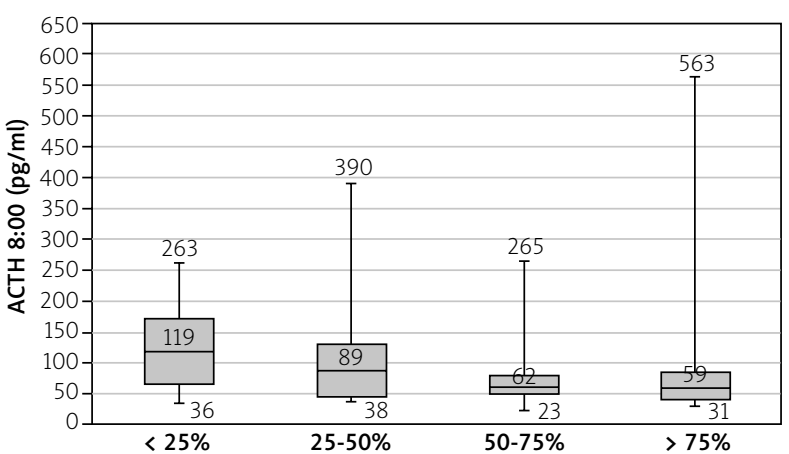

Fig. 2. ACTH concentration at 8:00 (median, interquartile range, and range) by MGMT expression category.

sion was associated with lower tumour aggressiveness assessed in ancillary studies.

Our cohort comprised patients with typical features of Cushing's disease. The mean age and sex ratio in our cohort were similar to previous studies among patients with corticotroph tumours [29,30]. The remission rate in our cohort $(-60 \%)$ was below the median from over 40 studies ( $80 \%)$, probably because the proportion of macroadenomas among our patients was high [33].

Our study provides evidence on the expression of MGMT among a non-selected cohort of patients with corticotroph adenomas. Half of all corticotroph tumours in our study had high MGMT expression (>75\% of cells). This finding strongly suggests that temozolomide would not be appropriate as a firstline treatment. Temozolomide seems better as a second-line treatment, after surgery, because recurring tumours tend to have low MGMT expression and are more susceptible to this type of chemotherapy [32]. 
Table III. Relationship between histopathological tumour characteristics and early clinical remission

\begin{tabular}{|lcc|}
\hline \multirow{2}{*}{ Predictor } & \multicolumn{2}{c|}{ Univariate logistic regression } \\
\cline { 2 - 3 } & OR $(95 \% \mathrm{Cl})$ & $p$-value \\
\hline MGMT (category) & $1.83(1.20-2.81)$ & 0.005 \\
\hline Ki-67 (category) & $0.55(0.23-1.32)$ & 0.182 \\
\hline p53 (category) & $0.82(0.35-1.19)$ & 0.641 \\
\hline Mitotic index $(\geq 2$ vs. $<2)$ & $0.33(0.05-2.10)$ & 0.238 \\
\hline $\begin{array}{l}\text { Electron microscopy } \\
\text { (SG-ACTH vs. DG-ACTH) }\end{array}$ & $0.30(0.09-1.08)$ & 0.065 \\
\hline
\end{tabular}

MGMT - 0-6-methylguanine-DNA methyltransferase. Expression categories were treated as ordered variables. All expression categories as in Table II.

In contrast to our study, Salehi et al. found that nearly a half of corticotroph pituitary adenomas had low MGMT expression (< $10 \%$ of cells) [36]. In that study, however, a third of all tumours were Crooke cell adenomas, which are more aggressive than other corticotroph tumours. In another study, nearly $80 \%$ of corticotroph pituitary tumours had low MGMT expression, but the scoring method was different than in our study [45].

In line with previous research, we did not find any significant relationship between MGMT expression and age [9]. We found that MGMT expression was lower in men than in women. Similarly, in the study of Salehi et al., MGMT expression > 25\% was seen among women only, although those authors concluded that there was no relationship between MGMT expression and sex [41]. In contrast, this relationship was not significant for other pituitary tumour studies [9]. We also found that higher MGMT expression was significantly associated with lower tumour diameter and hormone production. This finding may be specific for ACTH-producing adenomas [41] because it has not been reported in other pituitary tumours [9]. MGMT expression was not related to cavernous sinus invasion among our patients. Other factors, such as mediators of angiogenesis, might be implicated [25].

We found that increased MGMT expression was associated with a low expression of established histopathological markers of aggressiveness of pituitary tumours. In our cohort, higher MGMT expression was related to lower Ki-67 expression, which is associated with increased invasiveness of pituitary adenomas [27,33]. Similarly, higher MGMT expression was found in tumours that had low p53 expression and a lower number of mitotic figures, which
Table IV. Relationship between MGMT expression and early clinical remission corrected for tumour size (logistic regression)

\begin{tabular}{|lcc|}
\hline & OR $(95 \% \mathrm{Cl})$ & $p$-value \\
\hline MGMT (category) & $1.55(0.96-2.50)$ & 0.074 \\
\hline $\begin{array}{l}\text { Tumour size } \\
\text { (microadenoma vs. } \\
\text { macroadenoma) }\end{array}$ & $0.12(0.04-0.39)$ & $<0.001$ \\
\hline
\end{tabular}

MGMT - 0-6-methylguanine-DNA methyltransferase. Expression categories were treated as ordered variables. All expression categories as in Table II.

both indicate a low tumour proliferation rate $[15,26]$. Moreover, higher MGMT expression was more likely in densely granulated tumours, which tend to be microadenomas with a low recurrence rate [10]. We confirmed previous reports that high MGMT expression was a favourable indicator of remission after surgery. In our study, MGMT expression was the only histopathological marker that significantly predicted remission.

Our findings support the use of temozolomide after failure of surgical treatment when MGMT expression is low. Although most corticotroph adenomas seem to have high MGMT expression, tumours that recur after surgery are more likely to have low MGMT expression and therefore be susceptible to temozolomide $[41,49]$. Several groups showed that temozolomide was effective among patients with aggressive pituitary tumours, including corticotroph adenomas [1,4,7,8,12,19,21,24,41]. Based on such findings, the European Society of Endocrinology recommends temozolomide monotherapy as the first-line chemotherapy for aggressive pituitary tumours or carcinomas after failure of standard therapies [35]. Because the response to temozolomide among patients with recurrent pituitary tumours in not universal, we need to find additional prognostic factors. It seems that MGMT might be such a factor. Several reports indicated that low MGMT expression is associated with a favourable response to temozolomide treatment [25]. One group suggested that MGMT expression in < $50 \%$ of cells was a predictor of successful temozolomide treatment among patients with atypical pituitary adenomas or pituitary carcinomas [2]. However, in a study among 7 patients with aggressive pituitary tumours, MGMT tumour expression did not predict the outcomes of temozolomide treatment [6]. From a practical standpoint, it seems that one trial course of temozolomide could help establish its efficacy, 
because first-course non-responders are unlikely to respond to further courses [7,36].

The limitations of our study need to be mentioned. First, the design was retrospective, which could bias data collection. However, the data were taken from a prospectively collected database maintained in our department. Moreover, all surgeries and assessments were done according to the same protocol. Second, we could not investigate how MGMT expression was related to the outcomes of temozolomide treatment.

The strengths of our work include a relatively large number of patients with corticotroph pituitary adenomas. Additionally, we assessed the relationship between MGMT tumour expression and other proliferation markers and laboratory examinations.

In conclusion, our investigation confirmed the value of MGMT expression in predicting the outcomes of transsphenoidal surgery for Cushing's disease. Moreover, we observed that low MGMT expression was associated with increased aggressiveness of corticotroph tumours. Temozolomide seems to be a suitable treatment for recurring and invasive corticotroph tumours, but more studies are needed to establish the criteria for its use in Cushing's disease.

\section{Acknowledgements}

The authors thank the clinical staff and patients who participated in the study. Medical editorial assistance was provided by Proper Medical Writing; funding for this support was provided by the Medical University of Warsaw.

\section{Funding}

The study was supported by the Warsaw Medical University and Military Institute of Medicine, Warsaw, Poland.

\section{Data availability}

Data are available upon request.

\section{Ethical approval}

The study was approved by the local Bioethics Committee and conducted in accordance with the International Conference on Harmonisation Guideline for Good Clinical Practice and the ethical principles of the Declaration of Helsinki.

\section{Disclosure}

The authors declare no conflict of interest.

\section{References}

1. Annamalai AK, Dean AF, Kandasamy N, Kovacs K, Burton $H$, Halsall DJ, Shaw AS, Antoun NM, Cheow HK, Kirollos RW, Pickard JD, Simpson HL, Jefferies SJ, Burnet NG, Gurnell M. Temozolomide responsiveness in aggressive corticotroph tumours: a case report and review of the literature. Pituitary 2012; 15: 276-287.

2. Bengtsson D, Schrøder HD, Andersen M, Maiter D, Berinder K, Rasmussen UF, Rasmussen ÅK, Johannsson G, Hoybye C, van der Lelym AJ, Petersson M, Ragnarsson O, Burman P. Long-term outcome and MGMT as a predictive marker in 24 patients with atypical pituitary adenomas and pituitary carcinomas given treatment with temozolomide. J Clin Endocrinol Metab 2015; 100: 1689-1698.

3. Biller BMK, Grossman AB, Stewart PM, Melmed S, Bertagna X, Bertherat J, Buchfelder M, Colao A, Hermus AR, Hofland LJ, Klibanski A, Lacroix A, Lindsay JR, Newell-Price J, Nieman LK, Petersenn S, Sonino N, Stalla GK, Swearingen B, Vance ML, Wass JA, Boscaro M. Treatment of adrenocorticotropin-dependent Cushing's syndrome: a consensus statement. J Clin Endocrinol Metab 2008; 93: 2454-2462.

4. Bruno OD, Juárez-Allen L, Christiansen SB, Manavela M, Danilowicz K, Vigovich C, Gómez RM. Temozolomide therapy for aggressive pituitary tumors: results in a small series of patients from Argentina. Int J Endocrinol 2015; 2015: 587893.

5. Burke CW, Adams CBT, Esiri MM, Morris C, Beevan JS. Transsphenoidal surgery for Cushing's Disease: does what is removed determine the endocrine outcome? Clin Endocrinol 1990; 33: 525-537.

6. Bush ZM, Longtine JA, Cunningham T, Schiff D, Jane JA, Vance ML, Thorner MO, Laws ER Jr, Lopes MB. Temozolomide treatment for aggressive pituitary tumors: Correlation of clinical outcome with 0-6-methylguanine methyltransferase (MGMT) promoter methylation and expression. J Clin Endocrinol Metab 2010; 95: 280-290.

7. Campderá M, Palacios N, Aller J, Magallón R, Martín P, Saucedo G, Lilienfeld H, Estrada J. Temozolomide for aggressive ACTH pituitary tumors: failure of a second course of treatment. Pituitary 2016; 19: 158-166.

8. Ceccato F, Lombardi G, Manara R, Emanuelli E, Denaro L, Milanese L, Gardiman MP, Bertorelle R, Scanarini M, D’Avella D, Occhi G, Boscaro M, Zagonel V, Scaroni C. Temozolomide and pasireotide treatment for aggressive pituitary adenoma: expertise at a tertiary care center. J Neurooncol 2015; 122: 189-196.

9. Dai C, Sun B, Liu X, Bao X, Feng M, Yao Y. O-6-Methylguanine-DNA methyltransferase expression is associated with pituitary adenoma tumor recurrence: a systematic meta-analysis. Oncotarget 2017; 8: 19674-19683.

10. Dogansen SC, Bilgic B, Yalin GY, Tanrikulu S, Yarman S. Clinical significance of granulation pattern in corticotroph pituitary adenomas. Turkish J Pathol 2019; 35: 9-14. 
11. Fealey ME, Scheithauer BW, Horvath E, Erickson D, Kovacs K, McLendon R, Lloyd RV. MGMT immunoexpression in silent subtype 3 pituitary adenomas: possible therapeutic implications. Endocr Pathol 2010; 21: 161-165.

12. Felker J, Patterson B, Wrubel D, Janss A. Successful treatment of a child with a prolactin secreting macroadenoma with temozolomide. J Pediatr Endocrinol Metab 2016; 29: 1413-1415.

13. Ferone D, Pivonello C, Vitale G, Zatelli MC, Colao A, Pivonello R. Molecular basis of pharmacological therapy in Cushing's disease. Endocrine 2014; 46: 181-198.

14. Gerson SL. MGMT its role in cancer aetiology and cancer therapeutics. Nat Rev Cancer 2004; 4: 296-307.

15. Hadzhiyanev A, Ivanova R, Nachev E, Elenkova A, Yaneva M, Zaharieva S, Marinov M, Surchev J, Ivanova A. Evaluation of prognostic utility of MIB-1 and p53 expression in pituitary adenomas: correlations with clinical behaviour and follow-up results. Biotechnol Biotechnol Equip 2014; 28: 502-507.

16. Invitti C, Giraldi FP, De Martin M, Cavagnini F. Diagnosis and management of Cushing's syndrome: results of an Italian multicentre study. J Clin Endocrinol Metab 1999; 84: 440-448.

17. Kaina B, Christmann M, Naumann S, Roos WP. MGMT: Key node in the battle against genotoxicity, carcinogenicity and apoptosis induced by alkylating agents. DNA Repair 2007; 6: 1079-1099.

18. Kawate H, Ihara K, Kohda K, Sakumi K, Sekiguchi M. Mouse methyltransferase for repair of 06-methylguanine and O4-methylthymine in DNA. Carcinogenesis 1995; 16: 1595-1602.

19. Knosp E, Steiner E, Kitz K, Matula C. Pituitary adenomas with invasion of the cavernous sinus space: a magnetic resonance imaging classification compared with surgical findings. Neurosurgery 1993; 33: 610-617.

20. Kurowska M, Nowakowski A, Zieliński G, Malicka J, Tarach JS, Maksymowicz M, Denew P. Temozolomide-induced shrinkage of invasive pituitary adenoma in patient with Nelson's syndrome: a case report and review of the literature. Case Rep Endocrinol 2015; 2015: 623092

21. Lasolle H, Cortet C, Castinetti F, Cloix L, Caron P, Delemer B, Desailloud R, Jublanc C, Lebrun-Frenay C, Sadoul JL, Taillandier L, Batisse-Lignier M, Bonnet F, Bourcigaux N, Bresson D, Chabre O, Chanson P, Garcia C, Haissaguerre M, Reznik Y, Borot S, Villa C, Vasiljevic A, Gaillard S, Jouanneau E, Assié G, Raverot G. Temozolomide treatment can improve overall survival in aggressive pituitary tumors and pituitary carcinomas. Eur J Endocrinol 2017; 176: 769-777.

22. Lau Q, Scheithauer B, Kovacs K, Horvath E, Syro LV, Lloyd R. MGMT immunoexpression in aggressive pituitary adenoma and carcinoma. Pituitary 2010; 13: 367-379.

23. Lloyd RV, Osamura YR, Kloppel G, Rosai J. WHO classification of tumours of endocrine organs. WHO Press 2017; 78-80.

24. Losa M, Mazza E, Terreni MR, McCormack A, Gill AJ, Motta M, Cangi MG, Talarico A, Mortini P, Reni M. Salvage therapy with temozolomide in patients with aggressive or metastatic pituitary adenomas: experience in six cases. Eur J Endocrinol 2010; 163: 843-851.

25. McCormack Al, Wass JAH, Grossman AB. Aggressive pituitary tumours: the role of temozolomide and the assessment of MGMT status. Eur J Clin Invest 2011; 41: 1133-1148.
26. Miao Y, Zong M, Jiang T, Yuan X, Guan S, Wang Y, Zhou D. A comparative analysis of ESM-1 and vascular endothelial cell marker (CD34/CD105) expression on pituitary adenoma invasion. Pituitary 2016; 19: 194-201.

27. Miermeister CP, Petersenn S, Buchfelder M, Fahlbusch R, Lüdecke DK, Hölsken A, Bergmann M, Knappe HU, Hans V, Flitsch J, Saeger W, Buslei R. Histological criteria for atypical pituitary adenomas - data from the German pituitary adenoma registry suggests modifications. Acta Neuropathol Commun 2015; 3: 50.

28. Mizoue T, Kawamoto H, Arita K, Kurisu K, Tominaga A, Uozumi T. MIB1 immunopositivity is associated with rapid regrowth of pituitary adenomas. Acta Neurochir 1997; 139: 426-432.

29. Nieman LK, Biller BMK, Findling JW, Newell-Price J, Savage MO, Stewart PM, Montori VM. The diagnosis of Cushing's syndrome: an endocrine society clinical practice guideline. J Clin Endocrinol Metab 2008; 93: 1526-1540.

30. Nishioka H, Yamada S. Cushing's disease. J Clin Med 2019; 8: 1951.

31. Patil CG, Prevedello DM, Lad SP, Vance ML, Thorner MO, Katznelson L, Laws ER. Late recurrences of Cushing's disease after initial successful transsphenoidal surgery. J Clin Endocrinol Metab 2008; 93: 358-362.

32. Petersenn S. Management of aggressive pituitary tumors a 2019 update. Horm Metab Res 2019; 51: 755-764.

33. Petersenn S, Beckers A, Ferone D, van der Lely A, Bollerslev J, Boscaro M, Brue T, Bruzzi P, Casanueva FF, Chanson P, Colao A, Reincke M, Stalla G, Tsagarakis S. Therapy of endocrine disease: outcomes in patients with Cushing 's disease undergoing transsphenoidal surgery: systematic review assessing criteria used to define remission and recurrence. Eur J Endocrinol 2015; 172: R227-239.

34. Pizarro CB, Oliveira MC, Coutinho LB, Ferreira NP. Measurement of Ki-67 antigen in 159 pituitary adenomas using the MIB-1 monoclonal antibody. Brazilian J Med Biol Res 2004; 37: 235243.

35. Raverot G, Burman P, McCormack A, Heaney A, Petersenn S, Popovic V, Trouillas J, Dekkers OM. European Society of Endocrinology Clinical Practice Guidelines for the management of aggressive pituitary tumours and carcinomas. Eur J Endocrinol 2018; 178: G1-24.

36. Raverot G, Sturm N, De Fraipont F, Muller M, Salenave S, Caron P, Chabre O, Chanson P, Cortet-Rudelli C, Assaker R, Dufour H, Gaillard S, François P, Jouanneau E, Passagia JG, Bernier M, Cornélius A, Figarella-Branger D, Trouillas J, Borson-Chazot F, Brue T. Temozolomide treatment in aggressive pituitary tumors and pituitary carcinomas: a French multicenter experience. J Clin Endocrinol Metab 2010; 95: 4592-4599.

37. Salehi F, Scheithauer BW, Kovacs K, Horvath E, Syro LV, Sharma S, Manoranjan B, Cusimano M. O-6-Methylguanine-DNA methyltransferase (MGMT) immunohistochemical expression in pituitary corticotroph adenomas. Neurosurgery 2012; 70 : 491-496.

38. Salehi F, Scheithauer BW, Moyes VJ, Drake WM, Syro LV, Manoranjan B, Sharma S, Horvath E, Kovacs K. Low immunohistochemical expression of MGMT in ACTH secreting pituitary 
tumors of patients with Nelson syndrome. Endocr Pathol 2010; 21: 227-229.

39. Sharma S, Salehi F, Scheithauer BW, Rotondo F, Syro LV, Kovacs K. Role of MGMT in tumor development, progression, diagnosis, treatment and prognosis. Anticancer Res 2009; 29: 3759-3768.

40. Syro LV, Ortiz LD, Scheithauer BW, Lloyd R, Lau Q, Gonzalez R, Uribe H, Cusimano M, Kovacs K, Horvath E. Treatment of pituitary neoplasms with temozolomide. Cancer 2011; 117: 454-462.

41. Takeshita A, Inoshita N, Taguchi M, Okuda C, Fukuhara N, Oyama K, Ohashi K, Sano T, Takeuchi Y, Yamada S. High incidence of low 06-methylguanine DNA methyltransferase expression in invasive macroadenomas of Cushing's disease. Eur J Endocrinol 2009; 161: 553-559.

42. Tanaka S, Yamamoto M, Morita M, Takeno A, Kanazawa I, Yamaguchi T, Yamada S, Inoshita N, Oki Y, Kurosaki M, Sugimoto $\mathrm{T}$. Successful reduction of ACTH secretion in a case of intractable Cushing`s disease with pituitary Crooke's cell adenoma by combined modality therapy including temozolomide. Endocr J 2019; 66: 701-708.

43. Tritos NA, Biller BMK. Current management of Cushing's disease. J Intern Med 2019; 286: 526-541.

44. Valassi E, Santos A, Yaneva M, Tóth M, Strasburger CJ, Chanson P, Wass JA, Chabre O, Pfeifer M, Feelders RA, Tsagarakis S, Trainer PJ, Franz H, Zopf K, Zacharieva S, Lamberts SW, Tabarin A, Webb SM; ERCUSYN Study Group: the European registry on Cushing's syndrome: 2-year experience Baseline demographic and clinical characteristics. Eur J Endocrinol 2011; 165 383-392.

45. Vallette-Kasic S, Dufour H, Mugnier M, Trouillas J, Valdes-Socin H, Caron P, Morange S, Girard N, Grisoli F, Jaquet P, Brue T. Markers of tumor invasion are major predictive factors for the long-term outcome of corticotroph microadenomas treated by transsphenoidal adenomectomy. Eur J Endocrinol 2000; 143: 761-768.

46. Wang Y, Li J, Tohti M, Hu Y, Wang S, Li W, Lu Z, Ma C. The expression profile of Dopamine D2 receptor, MGMT and VEGF in different histological subtypes of pituitary adenomas: a study of 197 cases and indications for the medical therapy. J Exp Clin Cancer Res 2014; 33: 56.

47. Witek P, Zieliński G, Szamotulska K, Zgliczyński W. Transsphenoidal surgery for Cushing`s disease: the role of early post-operative serum cortisol measurements as a predictor of success - a prospective study. Endokrynol Pol 2013; 64: 30-39.

48. Woo YS, Isidori AM, Wat WZ, Kaltsas GA, Afshar F, Sabin I, Jenkins PJ, Monson JP, Besser GM, Grossman AB. Clinical and biochemical characteristics of adrenocorticotropin-secreting macroadenomas. J Clin Endocrinol Metab 2005; 90: 4963-4969.

49. Zacharia BE, Gulati AP, Bruce JN, Carminucci AS, Wardlaw SL, Siegelin M, Remotti H, Lignelli A, Fine RL. High response rates and prolonged survival in patients with corticotroph pituitary tumors and refractory Cushing's disease from capecitabine and temozolomide (CAPTEM): a case series. Neurosurgery 2014; 74: 447-455. 